\title{
UCRL-JRNL-208839
}

LAWRENCE LIVERMORE N A T IO N A L LABORATORY

\section{Vehicular Storage of Hydrogen in Insulated Pressure Vessels}

S. M. Aceves, G. D. Berry, J. Martinez-Frias, F. Espinosa-Loza

January 5, 2005

International Journal of Hydrogen Energy 
This document was prepared as an account of work sponsored by an agency of the United States Government. Neither the United States Government nor the University of California nor any of their employees, makes any warranty, express or implied, or assumes any legal liability or responsibility for the accuracy, completeness, or usefulness of any information, apparatus, product, or process disclosed, or represents that its use would not infringe privately owned rights. Reference herein to any specific commercial product, process, or service by trade name, trademark, manufacturer, or otherwise, does not necessarily constitute or imply its endorsement, recommendation, or favoring by the United States Government or the University of California. The views and opinions of authors expressed herein do not necessarily state or reflect those of the United States Government or the University of California, and shall not be used for advertising or product endorsement purposes. 


\title{
Vehicular Storage of Hydrogen in Insulated Pressure Vessels
}

\author{
Salvador M. Aceves, Gene D. Berry, Joel Martinez-Frias, Francisco Espinosa-Loza \\ Lawrence Livermore National Laboratory \\ 7000 East Avenue, L-644 \\ Livermore, CA 94550, USA \\ saceves@LLNL.GOV \\ (925) 422 0864, fax (925) 4237914
}

\begin{abstract}
This paper describes the development of an alternative technology for storing hydrogen fuel onboard automobiles. Insulated pressure vessels are cryogenic-capable pressure vessels that can accept cryogenic liquid fuel, cryogenic compressed gas or compressed gas at ambient temperature. Insulated pressure vessels offer advantages over conventional $\mathrm{H}_{2}$ storage approaches. Insulated pressure vessels are more compact and require less carbon fiber than $\mathrm{GH}_{2}$ vessels. They have lower evaporative losses than $\mathrm{LH}_{2}$ tanks, and are much lighter than metal hydrides.

After outlining the advantages of hydrogen fuel and insulated pressure vessels, the paper describes the experimental and analytical work conducted to verify that insulated pressure vessels can be used safely for vehicular $\mathrm{H}_{2}$ storage. The paper describes tests that have been conducted to evaluate the safety of insulated pressure vessels. Insulated pressure vessels have successfully completed a series of DOT, ISO and SAE certification tests. A draft procedure for insulated pressure vessel certification has been generated to assist in a future commercialization of this technology. An insulated pressure vessel has been installed in a hydrogen fueled truck and it is currently being subjected to extensive testing.
\end{abstract}


Keywords: hydrogen storage, cryogenic hydrogen, pressure vessels

\section{Introduction}

Hydrogen $\left(\mathrm{H}_{2}\right)$ differs from other fuels in that it can be produced (and used) without releasing the potent greenhouse gas $\mathrm{CO}_{2}$, by simple decomposition of water $\left(\mathrm{H}_{2} \mathrm{O}\right)$ using electricity and/or heat from solar, wind, fission, or fusion power sources. As a versatile and universal carbonless energy carrier, $\mathrm{H}_{2}$ is a necessary element for future energy systems aimed at being free of air pollution, $\mathrm{CO}_{2}$, and other greenhouse gases. If generated from renewable energy, $\mathrm{H}_{2}$ becomes the crucial link in an inexhaustible global fuel cycle based on the cleanest, most abundant, natural, and elementary substances: $\mathrm{H}_{2}, \mathrm{O}_{2}$, and $\mathrm{H}_{2} \mathrm{O}$.

The physical and chemical properties of hydrogen make its utilization superior to fossil fuels. $\mathrm{H}_{2}$ is a simple, non-toxic molecule that generates power cleanly and efficiently, even silently and without combustion, if desired. Widespread use of $\mathrm{H}_{2}$ has been challenging, however, because of its low energy density relative to conventional (hydrocarbon) fuels. Energy density fundamentally drives the feasibility of $\mathrm{H}_{2}$-fueled transportation by determining the capital, materials, volume, and energy needed for onboard storage.

These economic and physical consequences of energy density, in turn, become strategic, placing limits on the scale, efficiency, cost, range, and shape of both $\mathrm{H}_{2}$ vehicles and the refueling infrastructure(s) linking the production of $\mathrm{H}_{2}$ with its use onboard vehicles. Consequently, improvements in the technology, economics, and energetics of onboard hydrogen storage will likely do the most to speed and shape the transition to $\mathrm{H}_{2}$ as a universal transportation fuel.

Quite unlike polyatomic hydrocarbon fuels such as gasoline $\left(\mathrm{C}_{8} \mathrm{H}_{18}\right), \mathrm{H}_{2}$ consists of just two monovalent atoms. This unique structure gives $\mathrm{H}_{2}$ extreme combustion characteristics (e.g. low ignition energy, low emissivity, wide flammability limits, high flame speed) and physical properties (high diffusivity, thermal conductivity, buoyancy, and incompressibility). An 
extremely low boiling point $(20.3 \mathrm{~K})$, second only to helium, gives $\mathrm{LH}_{2}$ an exceptionally large coefficient of thermal expansion. $\mathrm{LH}_{2}$ expands over $30 \%$ between $20 \mathrm{~K}$ and $30 \mathrm{~K}$. Particularly striking is the very low atomic density of $\mathrm{H}_{2}$ both as a compressed gas and as a cryogenic liquid [1]. There are fewer hydrogen atoms in $\mathrm{LH}_{2}$ (by volume) than in metal hydrides, most fuels, and common molecular liquids such as octane $\left(\mathrm{C}_{8} \mathrm{H}_{18}\right)$, ethanol $\left(\mathrm{CH}_{3} \mathrm{CH}_{2} \mathrm{OH}\right)$, methanol $\left(\mathrm{CH}_{3} \mathrm{OH}\right)$, cryogenic liquid methane $\left(\mathrm{LCH}_{4}\right)$, ammonia $\left(\mathrm{NH}_{3}\right)$, hydrazine $\left(\mathrm{N}_{2} \mathrm{H}_{4}\right)$, hydrogen peroxide $\left(\mathrm{H}_{2} \mathrm{O}_{2}\right)$, and even $\mathrm{H}_{2} \mathrm{O}$ (Figure 1).

Considering the importance of storage in achieving a smooth transition to the $\mathrm{H}_{2}$ economy, and the serious technical challenges associated with $\mathrm{H}_{2}$ storage, the authors of this paper have been investigating the applicability of an alternative approach for vehicular $\mathrm{H}_{2}$ storage: insulated pressure vessels. This paper discusses the advantages of insulated pressure vessels with respect to current $\mathrm{H}_{2}$ storage technologies (liquid $\mathrm{H}_{2}$, compressed $\mathrm{H}_{2}$ and $\mathrm{H}_{2}$ absorption in hydrides). The paper also describes the experimental effort dedicated to demonstrate the safety of operation of insulated pressure vessels for vehicular $\mathrm{H}_{2}$ storage.

\section{Hydrogen Storage Technologies}

There are at least three viable technologies for storing hydrogen fuel in cars. They are cryogenic liquid hydrogen $\left(\mathrm{LH}_{2}\right)$, compressed hydrogen gas $\left(\mathrm{GH}_{2}\right)$ and metal hydride absorption. The advantages and disadvantages of each are discussed briefly:

Liquid Hydrogen $\left(\mathbf{L} \mathbf{H}_{2}\right)$ : The main advantage of $\mathrm{LH}_{2}$ is its high density at low pressure, which enables light and compact vehicular storage [2] and efficient delivery by truck. $\mathrm{LH}_{2}$ technologies have matured considerably in recent years, allowing rapid ( 3 minute) refueling with no evaporative losses [3] and storage vessels with extremely low heat transfer rates from the environment $(\sim 1 \mathrm{~W})[4]$. However, even at these low heat transfer rates, evaporative losses remain an issue, as $\mathrm{H}_{2}$ typically has to be vented from the vessel after 3-5 days of inactivity. In extreme cases (long periods of inactivity), evaporative losses may deplete the 
hydrogen in the vehicle, leaving the driver stranded. Another disadvantage of $\mathrm{LH}_{2}$ storage is the substantial amount of electricity required for liquefying the $\mathrm{H}_{2}$ (up to $40 \%$ of the lower heating value). Finally, $\mathrm{LH}_{2}$ expands considerably as it warms between $20 \mathrm{~K}$ and the critical point $(33 \mathrm{~K})$. Therefore, $\mathrm{LH}_{2}$ tanks are fueled only 85 to $95 \%$ full to prevent $\mathrm{LH}_{2}$ spills, leaving $5-15 \%$ of empty space (ullage).

Compressed Gaseous Hydrogen $\left(\mathbf{G H}_{2}\right)$ : $\mathrm{GH}_{2}$ has become a viable technology for vehicular hydrogen storage due to the great improvements in high strength composite fibers that have been achieved over the last 20 years. Lightweight $\mathrm{GH}_{2}$ vessels are now available at extremely high pressures (700 atm; 10,000 psi). Future pressure vessels operating at even higher pressure (2000 atm; 29,000 psi) would reach a gas density similar to the density of $\mathrm{LH}_{2}$ [5]. In addition to this, storage of compressed gaseous fuels is a well established technology, broadly used in natural gas vehicles, and compression is an efficient procedure for increasing the density of $\mathrm{H}_{2}$, typically requiring electric energy equivalent to about $10 \%$ of the lower heating value of $\mathrm{H}_{2}$. On the negative side, $\mathrm{H}_{2}$ heats up considerably as it is pumped into a storage vessel, reducing the density of storage. At high pressure, $\mathrm{H}_{2}$ is not an ideal gas, considerably reducing the increase in density that can be obtained by increasing the pressure. $\mathrm{GH} 2$ also stores considerable mechanical compressive energy $(\sim 0.6 \mathrm{kWh} / \mathrm{kg} \mathrm{H}$ ), which can be destructively released in case of vessel failure. Finally, delivery of hydrogen to the fueling station (either by truck or by pipeline) may be difficult and/or expensive. Hydrogen can be delivered as $\mathrm{LH}_{2}$ and vaporized at the station. However, liquefying hydrogen for delivery negates the energy gains that could otherwise be obtained by avoiding liquefaction.

Metal Hydrides: Hydrogen can potentially be stored at high density (Figure 1) and low pressure by absorption in metallic hydrides. While most metal hydrides are too heavy, expensive or bond too strongly to hydrogen, recent research has identified sodium alanate $\left(\mathrm{NaAlH}_{4}\right)$ as a potentially practical hydride for vehicular applications [6]. However, multiple 
issues remain. Hydrides release considerable thermal energy as they absorb hydrogen and therefore require significant thermal energy $\left(10-20 \%\right.$ of the $\mathrm{H}_{2}$ lower heating value) input to release $\mathrm{H}_{2}$. Therefore, hydride beds typically need to be built with heating and cooling passages to allow refueling and desorption in a reasonable time, considerably reducing the system volumetric and gravimetric energy storage density. Desorption may require high temperature (400 $\mathrm{K}$ for alanates), which may not be available as waste heat from PEM fuel cells or high efficiency, high compression ratio internal combustion engines.

\section{Insulated Pressure Vessels}

The proposed alternative to vehicular hydrogen storage consists of storing fuel in an insulated pressure vessel that has the capability to operate at cryogenic temperature $(20 \mathrm{~K})$, and at high pressure (240 atm or higher). This vessel can be fueled exclusively with $\mathrm{LH}_{2}$, or it can be fueled flexibly with $\mathrm{LH}_{2}$, cryogenic $\mathrm{GH}_{2}$, or ambient temperature $\mathrm{GH}_{2}$. In both modes of operation insulated pressure vessels present advantages with respect to conventional $\mathrm{LH}_{2}$ and $\mathrm{GH} 2$ vessels. These advantages are discussed next.

Insulated Pressure Vessels Fueled Exclusively with $\mathbf{L H}_{2}$ : If the insulated pressure vessel is always fueled with $\mathrm{LH}_{2}$, it becomes a compact vessel that goes a long way toward solving most of the problems associated with $\mathrm{LH}_{2}$ tanks: evaporative losses after a short period of inactivity, high evaporative losses for short daily driving distances, danger of being stranded due to fuel evaporation and need for considerable (10-20\%) ullage space.

The dormancy (period of inactivity before a vessel releases hydrogen to reduce pressure build up) can be calculated from the first law of thermodynamics [7] and the properties of $\mathrm{H}_{2}[5]$ as a function of vessel maximum operating pressure. The results are shown in Figure 2. It is assumed that the pressure vessel is fueled with $\mathrm{LH}_{2}$ at $21 \mathrm{~K}$ and $1 \mathrm{~atm}$ and then parked until the $\mathrm{H}_{2}$ pressure reaches the maximum operating pressure of the vessel. At this point, the $\mathrm{H}_{2}$ has to be released from the vessel to keep the pressure at an acceptable level. It is assumed 
that the vessel stores $5 \mathrm{~kg}$ of $\mathrm{H}_{2}$ and heat transfer rate into the vessel is 1 Watt. The vessel is fueled to an $84 \%$ level (ullage is $16 \%$ ). Figure 2 shows that the dormancy increases quickly as the operating pressure of the vessel increases. At the operating pressure of today's liquid hydrogen tanks ( $\sim 6 \mathrm{~atm})$, the dormancy is 5 days. A sudden change in slope is observed in the figure after day 5 as the hydrogen leaves the two phase region and becomes a supercritical fluid. The dormancy reaches 2 weeks at 130 atm and 18 days at 200 atm. Further increases in dormancy can be obtained by increasing the pressure beyond $200 \mathrm{~atm}$. The results in Figure 2 neglect the thermal capacity of the vessel as well as the conversion between the two different states of nuclear spin arrangement (para-hydrogen and ortho-hydrogen). Both of these effects will tend to increase the dormancy of the vessels, especially at warmer temperatures $(T>80$ $\mathrm{K})$.

The minimum $\mathrm{H}_{2}$ temperature at the time of venting is also shown in Figure 2. The figure shows that as the operating pressure increases, the $\mathrm{H}_{2}$ contained in the vessel has to reach a higher temperature before venting is required. Therefore, it takes more heat transfer (and therefore more time) to reach the point at which venting is necessary.

Insulated pressure vessels also have considerable advantages in reducing evaporative losses during vehicle operation. This is illustrated in Figure 3. The figure shows evaporative losses, expressed as a percent of the total amount of $\mathrm{H}_{2}$ stored in the tank, as a function of daily driving distance and heat transfer rate into the tank. The solid lines show evaporative losses for $\mathrm{LH}_{2}$ tanks assuming 6 atm maximum operating pressure. Dotted lines show evaporative losses for an insulated pressure vessel with 240 atm maximum pressure. It is assumed that the vessels are initially fueled with $\mathrm{LH}_{2}$ at $21 \mathrm{~K}$ and $1 \mathrm{~atm}$, the ullage is $16 \%$, and the tank is installed in a vehicle with $34 \mathrm{~km} / \mathrm{L}$ (80 miles per gallon) gasoline equivalent fuel economy. The figure shows that the $\mathrm{LH}_{2}$ tank loses hydrogen whenever the vehicle is driven less than $23 \mathrm{~km}$ per day and the heat transfer rate is 1 Watt. Evaporative losses increase quickly as the 
daily driving distance decreases, as less driving results in more time available for evaporation. For insulated pressure vessels the same behavior is observed (more evaporative losses for less driving). However, much less driving is required to reduce losses to zero. At 1 Watt of heat transfer, it is enough to drive $4 \mathrm{~km}$ daily to reduce evaporative losses to zero.

The much reduced sensitivity of insulated pressure vessels to heat transfer compared to $\mathrm{LH}_{2}$ tanks can improve the volumetric efficiency, by allowing a thinner layer of insulation. This would result in a more compact system that can be better packaged into a vehicle.

Another important aspect illustrated in Figure 3 is the behavior of both tanks as the driving distance approaches zero. This is equivalent to leaving the vehicle unused for a very long period of time. $\mathrm{A} \mathrm{LH}_{2}$ tank that is left unused long enough to reach thermal equilibrium with the environment has a hydrogen storage density of $0.48 \mathrm{~kg} / \mathrm{m}^{3}$ (at $6 \mathrm{~atm}$ and $300 \mathrm{~K}$ ), which is less than $1 \%$ of the initial storage density in the vessel. Therefore, the vehicle may be stranded, unable to reach a fueling station. On the other hand, the insulated pressure vessel has a final density that is $29 \%$ of the initial density (at 240 atm and $300 \mathrm{~K}$ ), likely sufficient for $160 \mathrm{~km}$ of driving.. Therefore, a vehicle equipped with an insulated pressure vessel will never be stranded without fuel due to evaporative losses.

The need for ullage space reduces the storage capacity of $\mathrm{LH}_{2}$ tanks. $\mathrm{LH}_{2}$ tanks require a relatively large (5-15\%) ullage volume to avoid the venting of $\mathrm{LH}_{2}$. Insulated pressure vessels that operate at a pressure over $13 \mathrm{~atm}$ do not vent liquid hydrogen, since the hydrogen becomes a supercritical fluid before there is a need to vent. Because of this, it may be possible to considerably reduce or even eliminate ullage space in insulated pressure vessels, improving the energy density.

Finally, insulated pressure vessels may also gain a fuel density advantage with respect to $\mathrm{LH}_{2}$ tanks by enabling fueling with high pressure hydrogen at $\sim 20 \mathrm{~K}$. The density of $21 \mathrm{~K}$ 
hydrogen is $87 \mathrm{~kg} / \mathrm{m}^{3}$ at $240 \mathrm{~atm}$, significantly higher than the $70 \mathrm{~kg} / \mathrm{m}^{3}$ density of saturated $\mathrm{LH}_{2}$ at atmospheric pressure.

Flexibly Fueled Insulated Pressure Vessels: An insulated pressure vessel can be fueled flexibly with hydrogen at any state between $20 \mathrm{~K} \mathrm{LH}_{2}$ and ambient temperature $\mathrm{GH}_{2}$. The fueling flexibility of the insulated pressure vessels results in significant advantages. Energy requirements for $\mathrm{H}_{2}$ compression and cooling can be lower than for $\mathrm{LH}_{2}$ tanks because a car with an insulated pressure vessel can use, but does not require, cryogenic hydrogen fuel. A hybrid or fuel cell vehicle with $34 \mathrm{~km} / 1$ (80 mpg) gasoline equivalent fuel economy and a vessel with $100 \mathrm{~L}$ internal volume could be refueled with ambient temperature $\mathrm{GH}_{2}$ at 240 atm and achieve a $220 \mathrm{~km}$ range, suitable for the majority of trips. The additional energy, cost, and technological effort for cryogenic refueling need only be undertaken (and paid for) when the additional range is required for long(er) trips. With an insulated pressure vessel, vehicles can refuel most of the time with ambient temperature hydrogen, using less energy, avoiding evaporative losses and most likely at lower ultimate cost than $\mathrm{LH}_{2}$, but with more than double the storage capacity of ambient temperature compressed gas vessels. Use of compressed hydrogen in all trips under $200 \mathrm{~km}$ (which accounts for $85 \%$ of all the vehicle miles traveled in the USA [8]), could reduce the energy required for hydrogen storage by up to $75 \%$. relative to a vehicle that is always filled with $\mathrm{LH}_{2}$ (even neglecting possible evaporative losses from the $\mathrm{LH}_{2}$ tank). In addition to this, a flexibly fueled insulated pressure vessel would likely be very insensitive to heat transfer from the environment, if in practice, $\mathrm{LH}_{2}$ were only or chiefly used in long trips and therefore consumed quickly before significant evaporation can occur. Therefore, flexibly fueled insulated pressure vessels can be designed with a thin insulation to improve packaging characteristics or with an inexpensive insulation (possibly even powder insulation [9]) to reduce cost. 
The possible energetic advantage of using ambient temperature $\mathrm{GH}_{2}$ instead of $\mathrm{LH}_{2}$ is illustrated in Figure 4. This figure shows in solid lines the theoretical minimum energy necessary for compressing and cooling down the hydrogen from ambient conditions $(300 \mathrm{~K}$ and $1 \mathrm{~atm}$ ) to any desired temperature and density (the thermomechanical exergy [10]). The figure also shows pressure in dotted lines. Figure 4 shows that ambient temperature compression is the most energy efficient method to densify $\mathrm{H}_{2}$, since the theoretical (isothermal) work of compressing hydrogen rises only logarithmically with pressure. This applies both in theory as well as in practice. Compressing $\mathrm{GH}_{2}$ to $250-1000$ atm theoretically requires $1.5-2.0 \mathrm{kWh} / \mathrm{kg}$ and $2.5-4.0 \mathrm{kWh} / \mathrm{kg}$ in practice, substantially less energy than conventional $\mathrm{H}_{2}$ liquefaction $(10-14 \mathrm{kWh} / \mathrm{kg})$. Electrolysis at high pressure can compress $\mathrm{GH}_{2}$ at near theoretical efficiency.

Finally, insulated pressure vessels operating with low temperature $\mathrm{H}_{2}$ offer a safety advantage compared to ambient temperature $\mathrm{GH}_{2}$ storage. Figure 5 shows the maximum mechanical energy released by sudden expansion (e.g. in a vessel rupture) as a function of vessel pressure, for three temperatures $(80 \mathrm{~K}, 150 \mathrm{~K}$ and $300 \mathrm{~K})$. The results are counterintuitive. One $\mathrm{kg}$ of $\mathrm{H}_{2}$ stored at $70 \mathrm{~atm}$ and $300 \mathrm{~K}$ will release a theoretical maximum mechanical energy of $0.55 \mathrm{kWh}$ if suddenly (i.e. adiabatically) expanded to atmospheric pressure (cooling substantially in the process). This maximum energy release increases only slightly if $\mathrm{H}_{2}$ is stored at much higher pressures. Raising pressure from 70 atm to $1000 \mathrm{~atm}(1400 \%$ increase) increases the maximum (theoretical) mechanical energy release by only $10 \%$, while shrinking vessel volume $83 \%$, and strengthening the vessel wall many times over. Over the likely range of onboard $\mathrm{GH}_{2}$ storage pressures (350-1000 atm), the maximum mechanical energy release is nearly constant at $0.6 \mathrm{kWh}$ per $\mathrm{kg}$ of $\mathrm{GH}_{2}$. On the other hand, the theoretical maximum mechanical energy is a strong function of temperature. Reducing the temperature 
from $300 \mathrm{~K}$ to $150 \mathrm{~K}$ and especially to $80 \mathrm{~K}$ considerably reduces available mechanical energy, reducing the potential damage caused by a sudden rupture.

Summary of Insulated Pressure Vessel Analysis: The results presented in this section have shown that insulated pressure vessels present advantages with respect to $\mathrm{LH}_{2}$ and $\mathrm{GH}_{2}$ tanks. Insulated pressure vessels offer flexibility and savings, both in terms of energy and cost. From engineering and economic perspectives, insulated pressure vessels strike a versatile balance between the cost and bulk of ambient temperature compressed fuel storage, and the energy efficiency, thermal insulation and evaporative losses of cryogenic storage.

\section{Insulated Pressure Vessel Design}

Considering all the potential benefits of insulated pressure vessels described in the previous section, it is important to determine how to design a pressure vessel that is capable of operating at cryogenic temperature and high pressure. Of the available pressure vessel technologies commonly used for vehicular storage of hydrogen [11], it appears that aluminum-lined, composite-wrapped (Type 3) vessels have the most desirable combination of properties for this application, due to their low weight and affordable price.

Two insulated pressure vessel designs have been produced, both incorporating a Type 3 composite vessel. These are shown in Figures 6 and 7. Figure 6 is the first generation design, storing about $1 \mathrm{~kg}$ of hydrogen. Figure 7 is the second generation design, being able to store 9 $\mathrm{kg}$ of hydrogen. Both designs include a multi-layer vacuum insulation. Multi-layer insulation has a good thermal performance only under a high vacuum, at a pressure lower than $0.01 \mathrm{~Pa}$ [12]. Therefore, the use of multi-layer insulation requires that an outer jacket be built around the vessel. Insulated pressure vessel designs also include instrumentation for pressure, temperature and liquid level, as well as safety devices to avoid failure in case the hydrogen leaks into the vacuum space. Six vessels have been built for each of the two designs, and they have been used for DOT and SAE certification tests, and for incorporation into a 
demonstration vehicle.

\section{Insulated Pressure Vessel Testing}

While aluminum-lined, composite-wrapped pressure vessels are an appealing choice for insulated pressure vessels, they are not designed for use at cryogenic temperatures. This section describes work directed at verifying that the two insulated pressure vessel designs (Figures 6 and 7) can be safely used for vehicular hydrogen storage. This section describes multiple tests that have been conducted to evaluate the safety of insulated pressure vessel utilization. Insulated pressure vessels have been subjected to multiple DOT, ISO and SAE certification tests, and the vessels have always been successful in meeting the test criteria.

Pressure and Temperature Cycling: Pressure vessels have been cycled through 900 highpressure cycles and 100 low-temperature cycles. The cycles are alternated, running 9 pressure cycles followed by a temperature cycle, and repeating this sequence 100 times. This test is expected to represent fueling if these vessels were used in a hydrogen fueled car over $\sim 300,000$ miles. Aramid-aluminum and carbon fiber-aluminum pressure vessels have been cycled. The vessels did not fail during the test.

Burst Test: The aramid-aluminum and the carbon fiber-aluminum pressure vessels were burst-tested after being cycled at cryogenic temperature. The burst test was conducted according to the DOT standards [13]. Failure occurred by hoop mid cylinder separation, which is the preferred mode of failure. The burst pressure was $942 \mathrm{~atm}$, which is substantially higher than the minimum burst pressure of $720 \mathrm{~atm}$.

Testing with Liquid and Gaseous Hydrogen: A first-generation insulated pressure vessel has been tested with liquid and gaseous hydrogen. The vessel was first shock-tested and leak-tested. The insulated pressure vessel was then transported to a remote facility for testing with liquid hydrogen. Testing involved filling the vessel with $\mathrm{LH}_{2}$ to study the insulation performance, the performance of the sensors, and the problems involved with pumping the 
$\mathrm{LH}_{2}$ into the vessel. This test is expected to replicate what would happen to the vessel during fueling and operation in an exclusively $\mathrm{LH}_{2}$-fueled car. The test was conducted successfully. There was no damage to the vessel due to the low temperature operation, all the instrumentation operated properly at the low temperature.

Cycling, ambient temperature: 10,000 cycles from less than $10 \%$ of the service pressure to the $100 \%$ of service pressure, 10 cycles per minute maximum [13]. The insulated pressure vessel was able to withstand the cycling pressurization test without any evidence of visually observable damage, distortion, or leakage.

Cycling, environmental: 1) 5000 cycles from zero to service pressure with tank at $60^{\circ} \mathrm{C}$ and air at ambient temperature and 95\% humidity, 2) 5000 cycles from zero to service pressure with tank at $-51.1^{\circ} \mathrm{C}$ and air at ambient temperature, 3) 30 cycles from zero to service pressure, ambient conditions 4) burst test the cycled vessel [13]. The vessel was able to withstand the cycling pressurization test without any evidence of visually observable damage, distortion, or leakage.

Cycling, Thermal: 1) 10,000 cycles from zero to service pressure at ambient temperature, 2) 20 thermal cycles with tank temperature varying from $93.3^{\circ} \mathrm{C}$ to $-51.1^{\circ} \mathrm{C}$ at service pressure, 3) burst test the cycled vessel [13]. Each test cylinder must withstand the cycling pressurization test without any evidence of visually observable damage, distortion, or leakage. The test was conducted successfully.

Gunfire: Pressurize vessel with air or nitrogen to service pressure, and impact the vessel with a 0.30 caliber armor-piercing projectile with a speed of $853 \mathrm{~m} / \mathrm{s}$. The cylinder is positioned in such a way that the impact point is in the cylinder side wall at a $45^{\circ}$ angle with respect to the longitudinal axis of the cylinder. The distance from the firing location to the cylinder may not exceed 45.7 meters [13]. The test cylinder did not fail by fragmentation.

Bonfire: Pressurize cylinder with air or nitrogen to service pressure. Set pressure relief 
devices to discharge at $83 \%$ of the cylinder test pressure. The cylinder shall be exposed to fire until the gas is fully vented. The temperature measured on the surface tank exposed to the fire has to be between 850 and $900^{\circ} \mathrm{C}$ [13]. The venting of the gas must be predominantly through the pressure relief device. The test was conducted successfully.

Drop Test from $3 \mathrm{~m}:$ 1) The cylinder is dropped vertically onto the end, 2) the cylinder is dropped horizontally onto the side wall, 3) the cylinder is dropped onto a $3.8 \times 0.48 \mathrm{~cm}$ piece of angle iron, 4) after the drops, the vessel is cycled over 1000 pressure cycles from $10 \%$ of service pressure to the service pressure, at 10 cycles per minute [13]. The cylinder is then burst tested; the burst pressure of this vessel has to be at least $90 \%$ of the minimum burst pressure. The test was conducted successfully.

Cryogenic drop tests from $10 \mathrm{~m}$ : The drop test subjects a full-size vehicle fuel tank to a free-fall impact onto an unyielding surface from a height of $10 \mathrm{~m}$. The fuel tank impacts the outer shell on the critical area as determined by the manufacturer. The fuel tank is filled with an equivalent full weight of liquid nitrogen saturated to at least $50 \%$ of the maximum allowable working pressure of the fuel tank [14]. There shall be no loss of product for a period of 1 hour after the drop other than relief valve operation and loss of vapor between the filler neck and the secondary relief valve in the case of a test involving the filler neck. Loss of vacuum, denting of the vessel, piping and piping protection, and damage to the support system are acceptable. The test was conducted successfully.

Flame test with cryogenic fill: The tank should contain an equivalent full level of liquid nitrogen saturated at one half the maximum allowable working pressure (MAWP). The insulated pressure vessel was inverted and heated to an external temperature of $538^{\circ} \mathrm{C}$ for 20 minutes without the vessel reaching relief pressure [14].

Finite Element Analysis: In addition to all the testing, insulated pressure vessels have been extensively analyzed with a commercial finite element code [15]. The analysis focused on the 
thermal stresses generated when a vessel initially at ambient temperature is filled with liquid hydrogen and then pressurized with gaseous hydrogen. Multiple cryogenic-high pressure cycles were analyzed. The results showed that some plastic deformation occurs in the first cycle. However, the level of plastic deformation quickly converges to a relatively small value, and additional cycles do not increase the level of plastic deformation [16]. This result indicates that repeated cryogenic and high pressure cycling is unlikely to damage the vessel, in agreement with the experimental results.

\section{Insulated Pressure Vessel Certification}

All tests and analyses conducted to date indicate that insulated pressure vessels can safely be used to store cryogenic and ambient temperature compressed hydrogen for vehicular applications. The safety of insulated pressure vessels, along with their advantages for vehicular fuel storage opens the way for future commercialization of this technology. However, commercialization of insulated pressure vessels may still be limited due to the lack of a certification procedure. To address this issue we have developed a list of tests that may be applicable to determine whether an insulated pressure vessel is safe to operate. The list was developed by studying existing pressure vessel standards [13,14], to determine which tests need to be applied to insulated pressure vessels. From these standards we generated a list of 28 ambient temperature tests and 4 cryogenic tests. The list of tests has been documented into a report [17]. This report has been circulated to private industry and regulating organizations for their comments. It is considered that this report can be used as a starting point to generate an official certification procedure to be approved by a regulating agency, such as SAE or ISO.

\section{Technology Validation}

An insulated pressure vessel has been installed into a Ford Ranger pickup truck powered by a hydrogen internal combustion engine (Figure 8). The integration of the insulated pressure 
vessel into this vehicle has required multiple changes to the vehicle's fueling system to accommodate either liquefied or compressed hydrogen, as well as the location for fueling connectors, pressure relief devices, vents, etc. The vehicle is currently being tested at SunLine Transit (Thousand Palms, California). The vessel has been fueled multiple times with both $\mathrm{LH}_{2}$ and $\mathrm{GH}_{2}$, validating the dual mode operation capability of insulated pressure vessels. All of the truck operating parameters, including driving distance, fuel use, fuel pressure, temperature and level of fill are being continuously recorded in a computerized data acquisition system. Drivers and service personnel will thoroughly document fuel use, instrumentation performance, vehicle performance, refuelability issues, etc. Experiences obtained during operation are expected to greatly assist in future commercialization efforts by showing potential design improvements to be implemented in future vessel designs.

\section{Conclusions}

Insulated pressure vessels are being developed as a versatile technology for storage of hydrogen onboard light-duty vehicles. Insulated pressure vessels can accept fuel in three forms: cryogenic liquid, cryogenic compressed gas or ambient temperature compressed gas. This flexibility results in advantages compared to conventional storage technologies. Insulated pressure vessels are lighter than hydrides, more compact than ambient-temperature pressure vessels that store the same mass of fuel, and when compared to conventional cryogenic liquid fuel tanks they have lower evaporative losses and require lower energy input when filled with compressed gas.

For reduced cost and complexity it is desirable to use commercially available aluminum lined-fiber wrapped pressure vessels as components for the insulated pressure vessels. However, commercially available pressure vessels are not designed for operation at cryogenic temperature. A series of tests has been carried out to verify that commercially available pressure vessels can be operated at cryogenic temperature with no performance losses. All 
analyses and experiments to date indicate that no significant damage has occurred. Ongoing activities include a demonstration project in which an insulated pressure vessel has been installed in a vehicle and is being extensively tested.

\section{Acknowledgments}

The authors acknowledge the valuable contributions of Tim Ross, Vernon Switzer, Jim Fugina, Mark McCuller, Thomas Vi and Fernando Luna. This project is funded by the DOE Hydrogen Program, Sig Gronich, Sunita Satyapal and Antonio Bouza, Program Managers, and by the South Coast Air Quality Management District, Gary Dixon, Program Manager. Work performed under the auspices of the U.S. Department of Energy by University of California Lawrence Livermore National Laboratory under Contract W-7405-ENG-48.

\section{References}

1. Berry, G.D., Martinez-Frias, J., Espinoza-Loza,F., and Aceves, S.M., 2004, “Hydrogen Storage and Transportation," Encyclopedia of Energy, Volume 3, pp. 267-281, Elsevier Academic Press, New York, 2004.

2. Wolf, J., 2002, “Liquid Hydrogen Technology for Vehicles," MRS Bulletin, September, pp. $684-687$.

3. Hettinger, W. Michel, F., Ott, P., and Theissen, F., 1996, "Refueling Equipment for Liquid Hydrogen Vehicles," Proceedings of the $11^{\text {th }}$ World Hydrogen Energy Conference, Stuttgart, Germany, pp. 1135-1143.

4. Pehr, K., Burckhardt, S., Koppi, J., Korn, T., and Partsch, P., 2002, "Hydrogen, the Fuel of the Future, the BMW 750 HL," ATZ Auto Technology Journal, Vol. 104, No. 2, pp. 310.

5. McCarty, R.D., 1975,“Hydrogen: Its Technology and Implications, Hydrogen Properties, Volume III," CRC Press, Cleveland, Ohio. 
6. Sandrock, G., Gross, K., Thomas, G., Jensen, C., Meeker, D., and Takara, S., 2002, "Engineering Considerations in the Use of Catalyzed Sodium Alanates for Hydrogen Storage,” Journal of Alloys and Compounds, 330-332 (2002) 696-701.

7. Aceves, S.M. and Berry, G.D. 1998, “Thermodynamics of Insulated Pressure Vessels for Vehicular Hydrogen Storage,” ASME Journal of Energy Resources Technology, Vol. 120, No. 2, pp. 137-142.

8. Klinger, D., Kuzmyak JR., 1984, "Personal Travel in the United States," Vol. 1, 19831984, Nationwide Personal Transportation Study, Report PB89-235378, prepared for the US Department of Transportation, Office of Highway Information Management, Washington, DC.

9. Bunger, U., and Owren, G., 1996, "Development Potentials for Small Mobile Storage Tanks with Vacuum Powder Insulations," Proceedings of the $11^{\text {th }}$ World Hydrogen Energy Conference, Stuttgart, Germany, pp. 1043-1052.

10. Moran, M.J., 1982, “Availability Analysis: A Guide to Efficient Energy Use,” PrenticeHall, Inc., Englewood Cliffs, New Jersey.

11. Institute of Gas Technology, 1996, "Compressed Natural Gas Storage Optimization for Natural Gas Vehicles,” Gas Research Institute Report GRI-96/0364, Des Plaines, IL.

12. Kaganer, M.G., 1969, “Thermal Insulation in Cryogenic Engineering,” Israel Program for Scientific Translation Ltd., Jerusalem, Israel.

13. Code of Federal Regulations, Department of Transportation (CFR-DOT), 1996a, "Basic Requirements for Fully Wrapped Fiber Reinforced Aluminum Lined Cylinders," Title 49, CFR 107.105 Standard.

14. Society of Automotive Engineers (SAE), 1997, "Recommended Practices for LNG Powered Heavy-Duty Trucks," SAE.J2343.

15. ANSYS, Inc., 1999, “ANSYS Version 5.6 Technical Handbook,” Canonsburg, PA. 
16. Aceves, S.M., Martinez-Frias, J., Espinosa-Loza, F., "Performance Evaluation Tests of Insulated Pressure Vessels for Vehicular Hydrogen Storage," Proceedings of the World Hydrogen Energy Conference, Montreal, Canada, June 2002.

17. Almagro, R., 2004, "Development of a Procedure for Insulated Pressure Vessel Certification for Operation with Hydrogen and Natural Gas," Report to South Coast Air Quality Management District (SCAQMD) for Tasks 1.1 and 2.1 of project "Insulated Pressure Vessels: A Compact and Versatile Technology for Vehicular Hydrogen and Natural Gas Storage.” 


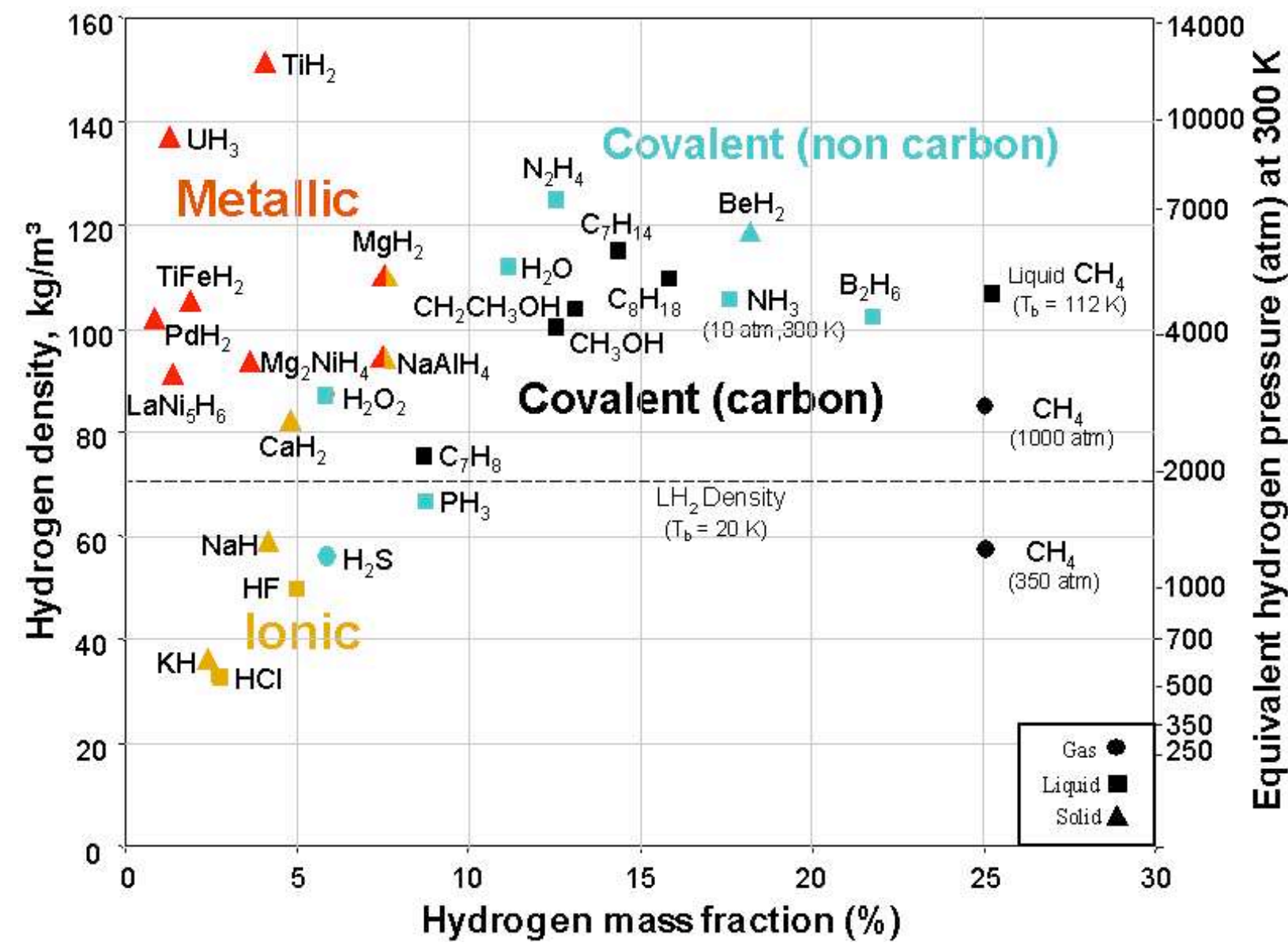

Figure 1. Density and mass fraction of hydrogen contained in substances spanning a spectrum of ionic, covalent, and metallic (both high temperature and low temperature) hydrides. Hydrocarbon fuels are also shown, including compressed methane $\left(\mathrm{CH}_{4}\right)$ at $300 \mathrm{~K}$. The right hand scale (non linear) shows the pressure needed to achieve an equivalent density of compressed hydrogen gas at $300 \mathrm{~K}$. The dashed line indicates that the density $\left(70 \mathrm{~kg} / \mathrm{m}^{3}\right)$ of liquid hydrogen $\left(\mathrm{LH}_{2}\right)$ at its boiling point $(20 \mathrm{~K})$ is substantially lower than the atomic hydrogen density of many compounds. 


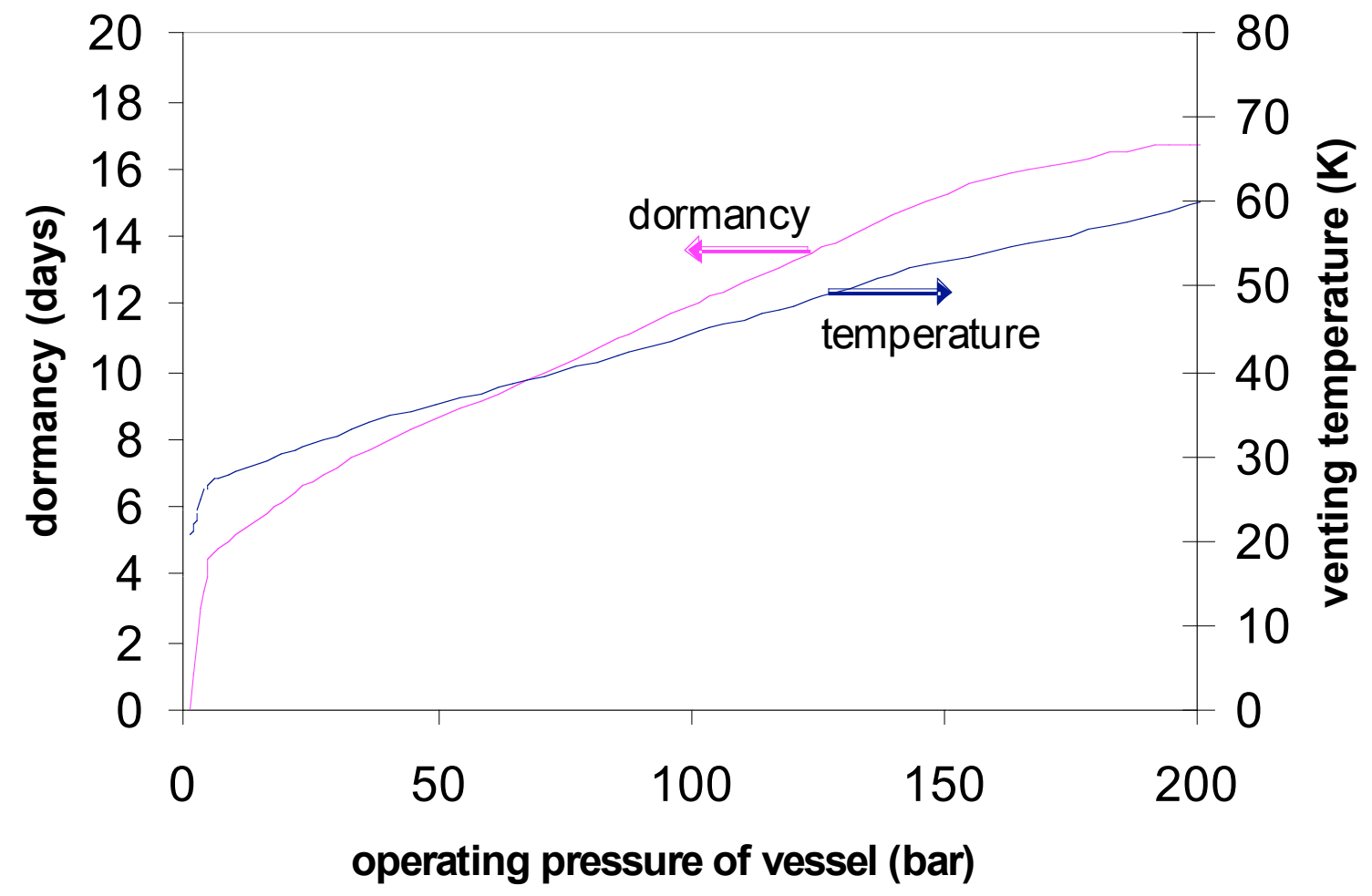

Figure 2. Dormancy (period of inactivity before a vessel starts having evaporative losses) and hydrogen temperature at the time of venting as a function of vessel maximum operating pressure. The vessel is fueled with $\mathrm{LH}_{2}$ at $21 \mathrm{~K}$ and 1 atm and then parked until the $\mathrm{H}_{2}$ pressure reaches the maximum operating pressure of the vessel. The vessel stores $5 \mathrm{~kg}$ of $\mathrm{H}_{2}$ and heat transfer rate into the vessel is 1 Watt. The vessel is fueled to an $84 \%$ level (ullage is $16 \%)$ 


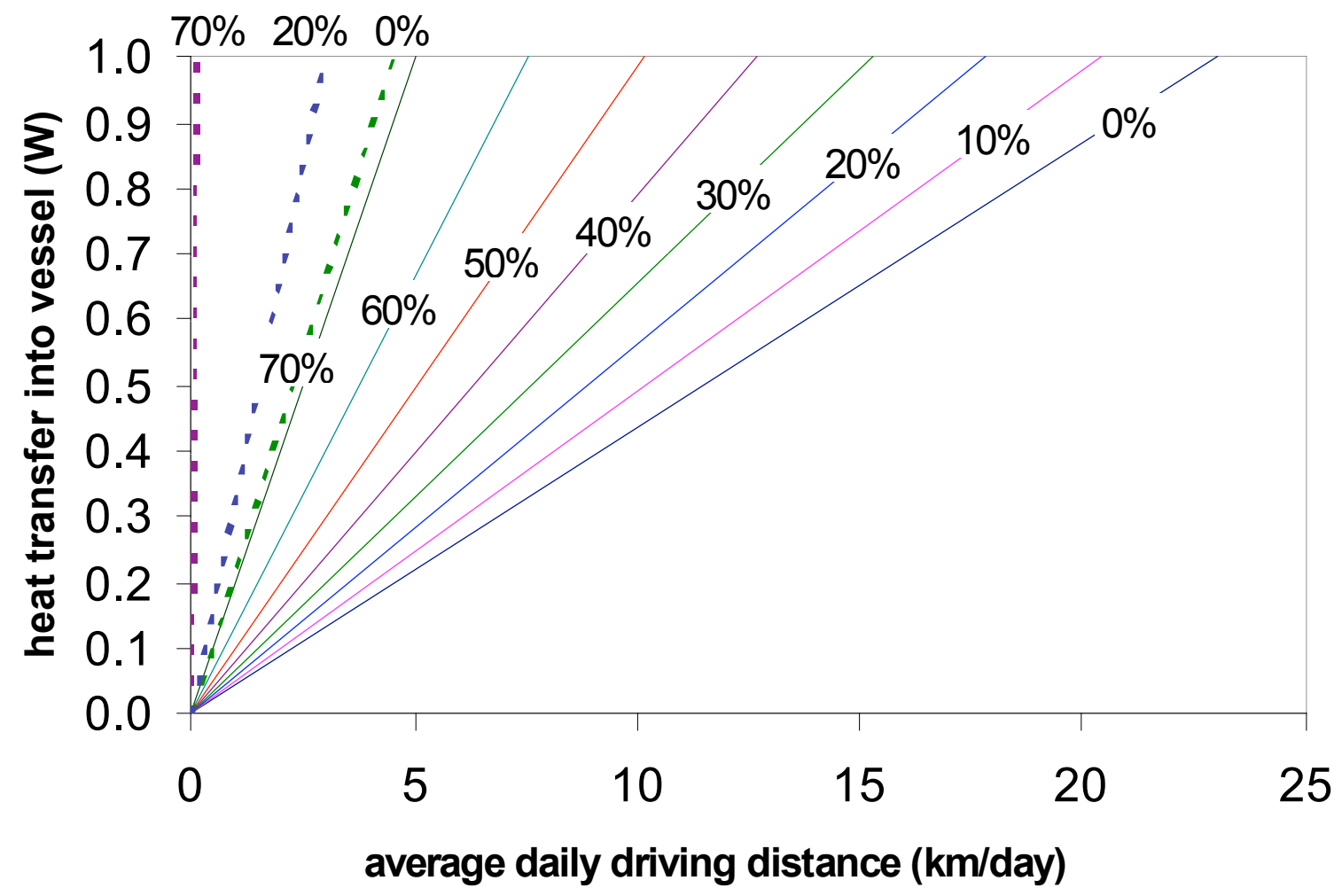

Figure 3. Cumulative fuel lost to venting (boiloff) of $\mathrm{H}_{2}$ vapor to due to continuous heat transfer (left axis) into the tank of an $80 \mathrm{mpg}$ equivalent $\mathrm{H}_{2}$ vehicle as a function of its average daily driving distance (horizontal axes). The solid lines in the figure show venting losses for a LH2 tank with 6 atm maximum working pressure, and the dotted lines are for an insulated pressure vessel with 240 atm maximum working pressure. The vehicle is assumed to refuel $84 \%$ full with $21 \mathrm{~K} \mathrm{LH}_{2}$. 


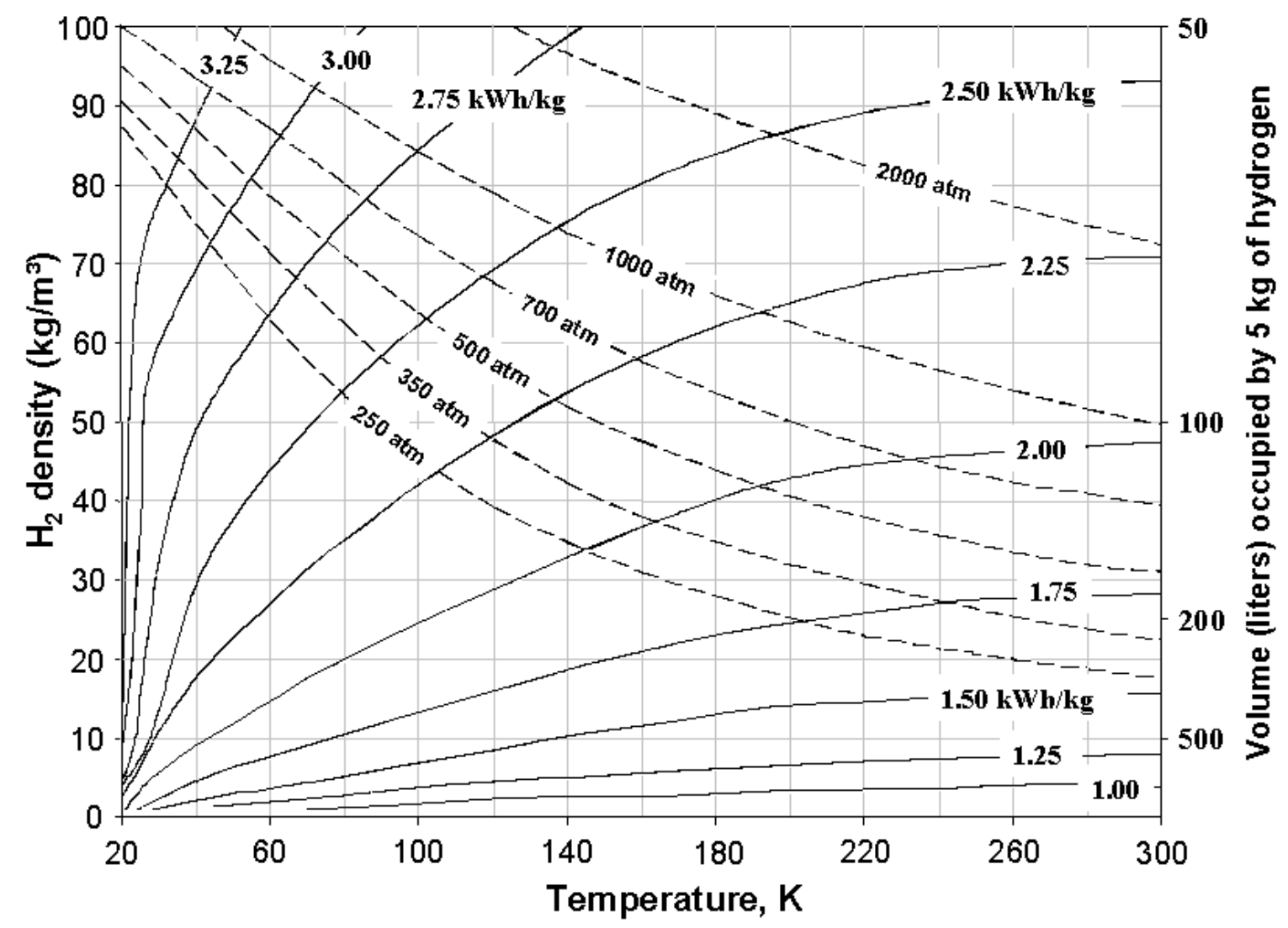

Figure 4. Theoretical minimum work to densify hydrogen from the reference gas density $\left(0.0818 \mathrm{~kg} / \mathrm{m}^{3}\right)$ at $300 \mathrm{~K}$ and 1 atmosphere pressure to the density (left axis) and temperature (bottom axis) shown. The corresponding volume occupied by $5 \mathrm{~kg}$ of hydrogen gas, energy equivalent to 5 gallons (19 liters) of gasoline, is shown on the right hand axis. Dashed lines indicate the pressure needed to achieve a given hydrogen density as a function of temperature. The density that can be achieved for a given amount of work (solid lines) declines sharply at cryogenic temperatures. The work necessary to convert orthohydrogen to parahydrogen is not included, but can be important for hydrogen stored more than a few days at temperatures below $60 \mathrm{~K}$. The ideal work of converting normal ( $75 \%$ ortho $) \mathrm{LH}_{2}$ to pure para- $\mathrm{LH}_{2}$ is $0.7 \mathrm{kWh} / \mathrm{kg}$ at the boiling point $(20 \mathrm{~K})$, where $\mathrm{LH}_{2}$ has a density of $70 \mathrm{kgH}_{2} / \mathrm{m}^{3}$. 


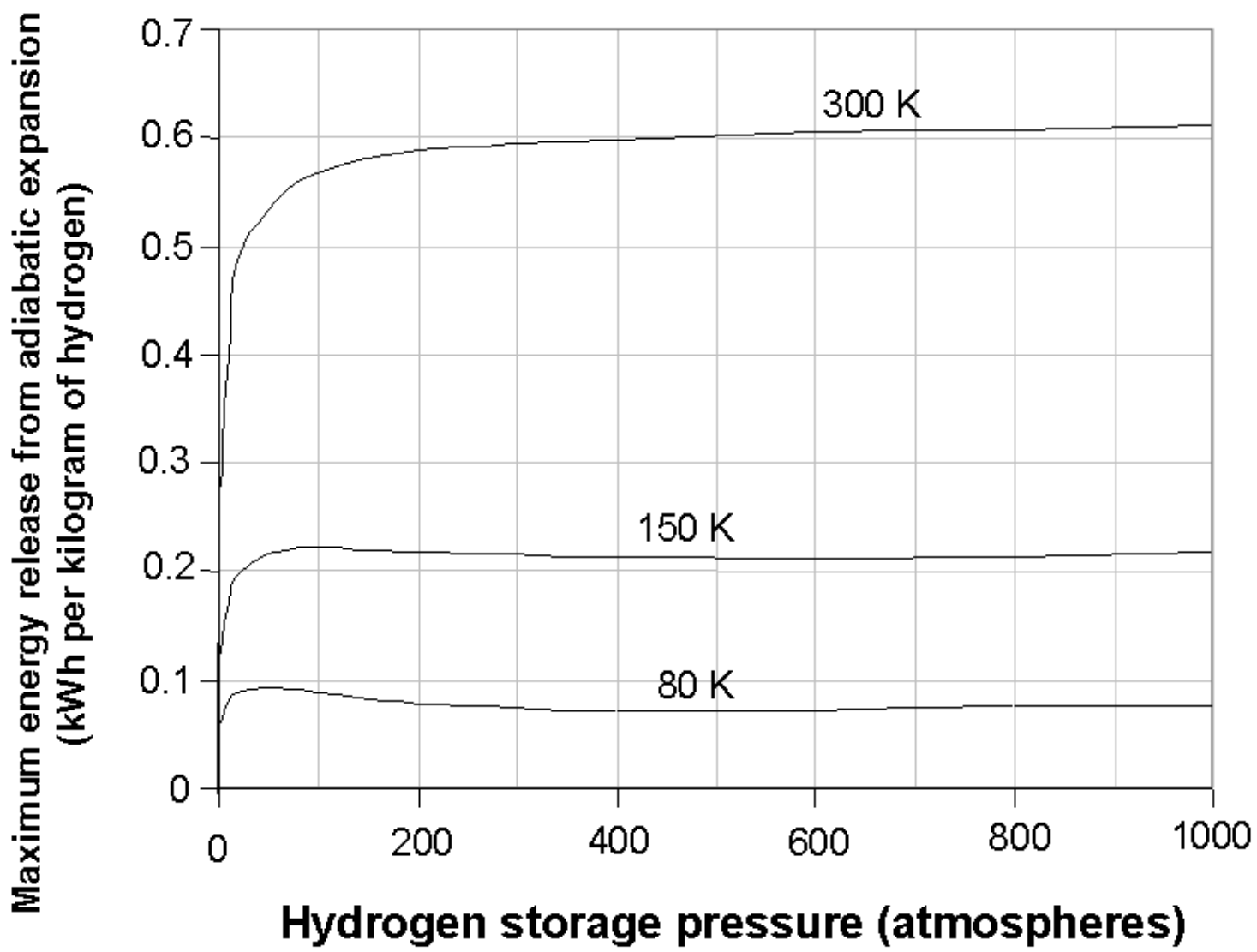

Figure 5. Maximum mechanical energy (per kilogram of hydrogen) released upon instantaneous expansion of $\mathrm{H}_{2}$ gas (e.g. from a pressure vessel) as a function of initial storage pressure at $80 \mathrm{~K}, 150 \mathrm{~K}$, and $300 \mathrm{~K}$. This mechanical energy is the theoretical maximum available work based on reversible adiabatic expansion from the pressure shown to $1 \mathrm{~atm}$, calculated from internal energy differences of $\mathrm{H}_{2}$ gas before and after isentropic expansion. For comparison, the chemical energy of hydrogen fuel is $33.3 \mathrm{kWh} / \mathrm{kg}$. 


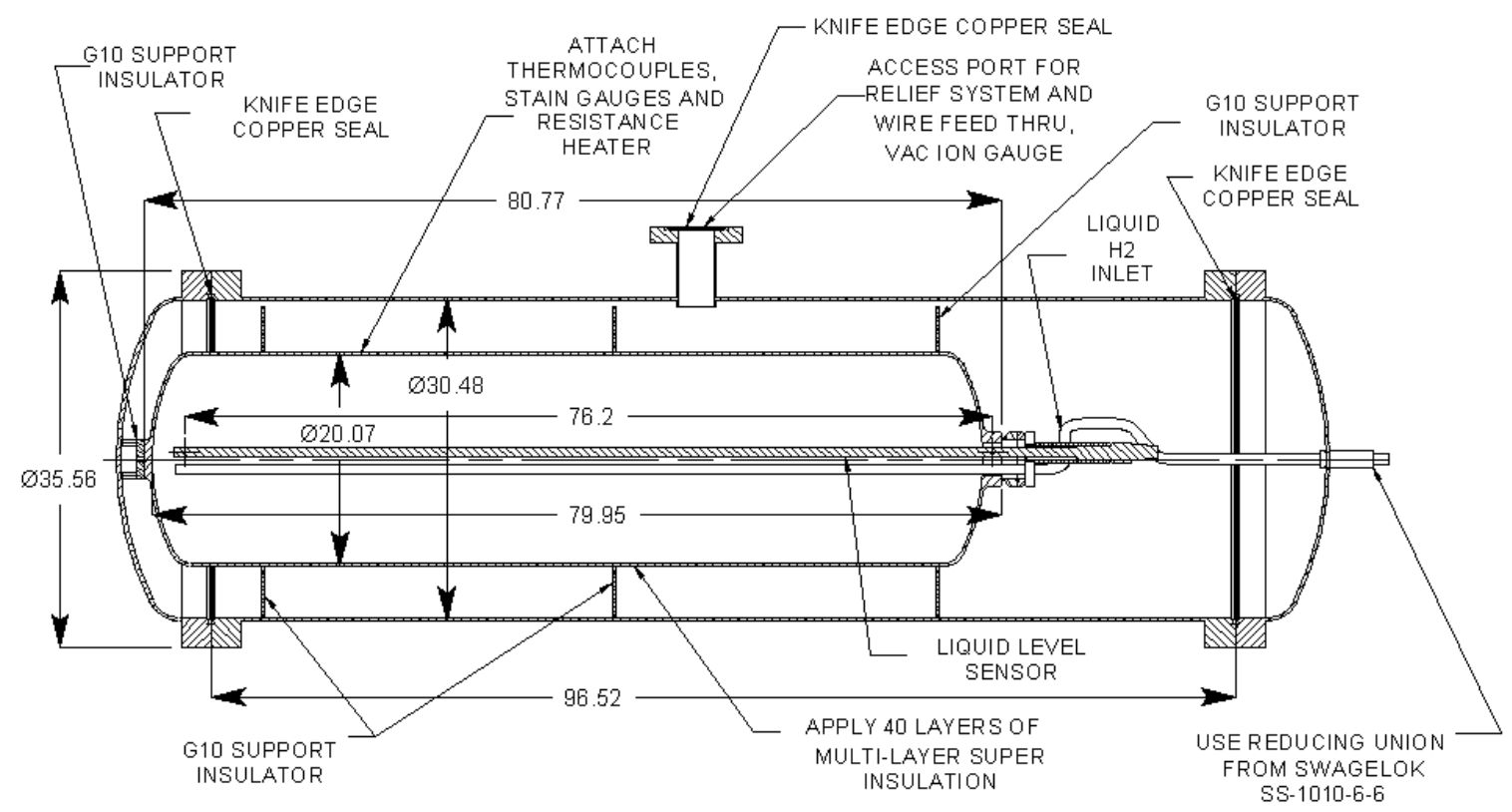

Figure 6. Design for the first generation of insulated pressure vessel. The figure shows a vacuum space, necessary for obtaining high thermal performance from the multilayer insulation, and instrumentation for pressure, temperature and level. Dimensions are given in $\mathrm{cm}$. 


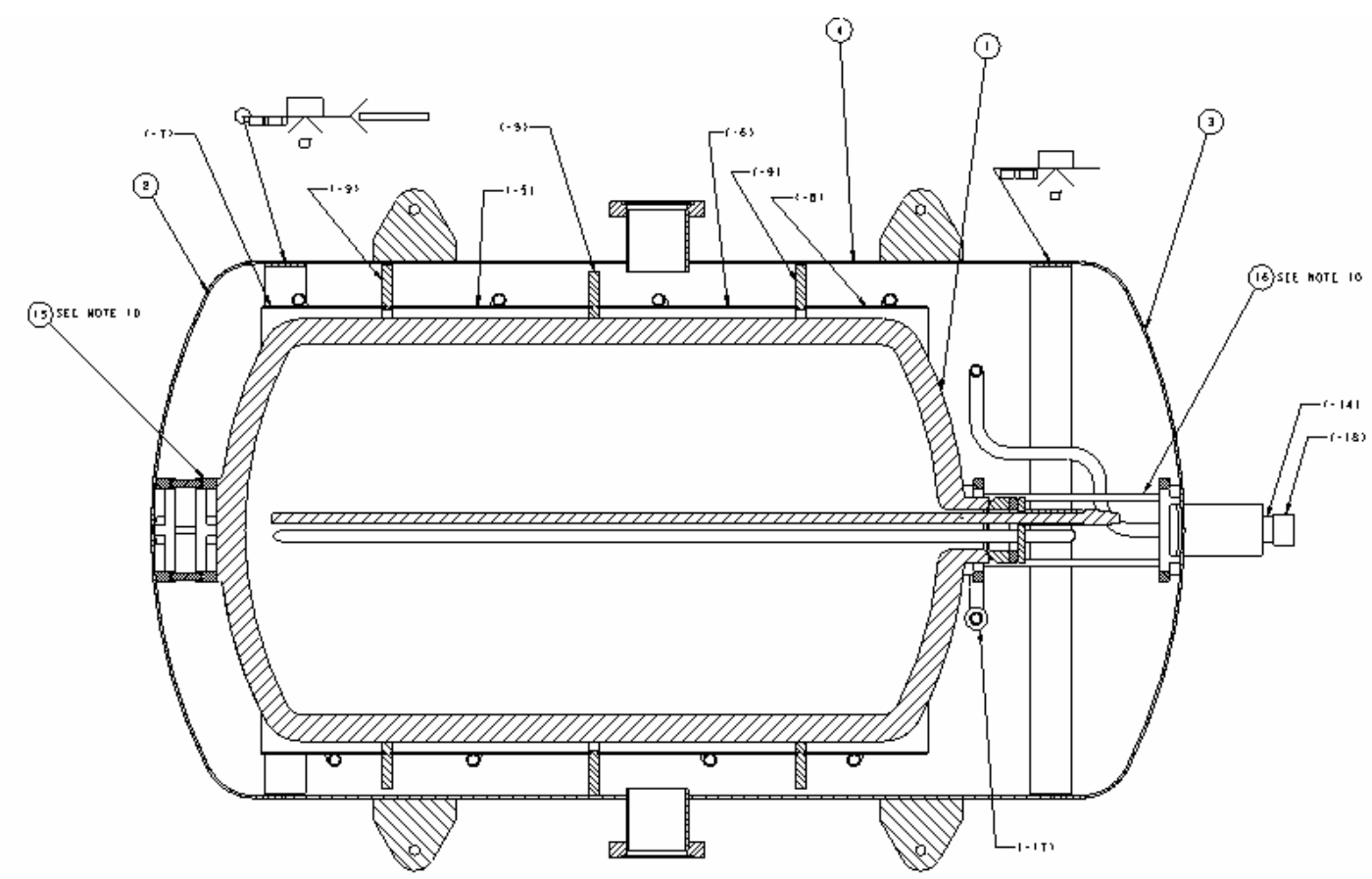

Figure 7. Design for the second generation of insulated pressure vessel. The figure shows a vacuum space, necessary for obtaining high thermal performance from the multilayer insulation, and instrumentation for pressure, temperature and liquid level. 


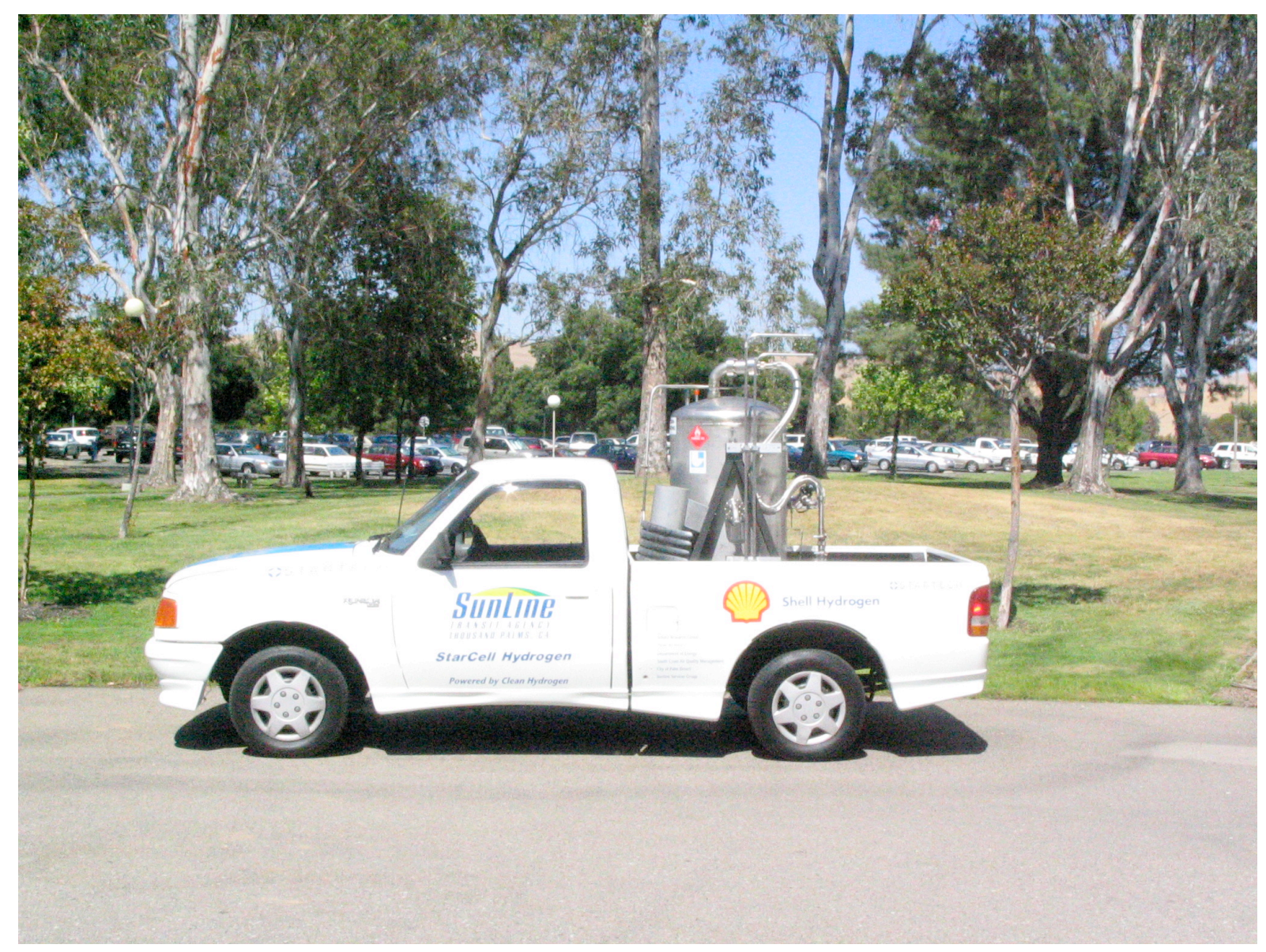

Figure 8. Hydrogen fueled truck equipped with insulated pressure vessel, now being demonstrated at SunLine Transit, Thousand Palms, California. 